\title{
Polypharmacy in the Elderly: A Marker of Increased Risk of Mortality in a Population-Based Prospective Study (NEDICES)
}

\author{
Candelas Gómez $^{a}$ Saturio Vega-Quirogab Félix Bermejo-Parejac, d, e \\ María José Medranof Elan D. Louis ${ }^{g, h, i, j} \quad$ Julián Benito-León ${ }^{c, d, e}$ \\ a'Eras del Bosque' Health Center, Palencia, ' 'Arévalo' Health Center, Arévalo, Ávila, and 'Department of Neurology, \\ University Hospital '12 de Octubre', 'Department of Medicine, Faculty of Medicine, Complutense University, \\ e Centro de Investigación Biomédica en Red sobre Enfermedades Neurodegenerativas (CIBERNED), and ${ }^{f}$ Vascular \\ Risk Factors Unit, National Center of Epidemiology, ISCIII, Madrid, Spain; 9 G.H. Sergievsky Center, hDepartment of \\ Neurology and 'Taub Institute for Research on Alzheimer's Disease and the Aging Brain, College of Physicians and \\ Surgeons, Columbia University, and 'Department of Epidemiology, Mailman School of Public Health, Columbia \\ University, New York, N.Y., USA
}

\section{Key Words}

Elderly people $\cdot$ Epidemiology $\cdot$ Mortality $\cdot$ Polypharmacy

\begin{abstract}
Background: Little information is available on the potential association between polypharmacy and risk of mortality. Objective: To determine in a population-based study whether polypharmacy is associated with increased risk of mortality in elderly persons. Methods: In this population-based, prospective study of 5,052 people aged 65 years and older (Neurological Disorders in Central Spain), current medications were recorded. Cox proportional hazards models, adjusted for sociodemographics and comorbidity factors, were used to assess the risk of death up to 13.3 years later, comparing the polypharmacy group ( $\geq 6$ drugs) to those who were taking 1-5 drugs and those in a nonmedicated group (0 drugs). Results: Out of 5,052 participants, 2,550 (50.5\%) died over a median follow-up of 6.5 years, including 361 (28.8\%) deaths among 931 nonmedicated participants, 1,946 (51.4\%) deaths among 3,787 participants taking 1-5 drugs daily, and $243(72.8 \%)$ among 334 participants on
\end{abstract}

(C) 2014 S. Karger AG, Basel

0304-324X/14/0614-0301\$39.50/0 polypharmacy. In an unadjusted Cox model, risk of mortality was increased in participants on polypharmacy [hazard ratio $(\mathrm{HR})=2.78,95 \%$ confidence interval $[\mathrm{Cl}]: 2.36-3.27, \mathrm{p}<$ $0.001)$ and in those taking between 1 and 5 drugs ( $H R=1.47$, $95 \% \mathrm{Cl}: 1.31-1.64, \mathrm{p}<0.001)$ versus those who were nonmedicated (reference group). In a Cox model that adjusted for a variety of demographic factors and comorbidities, HR remained increased in participants on polypharmacy ( $\mathrm{HR}=$ $1.83,95 \%$ Cl: $1.51-2.21, p<0.001)$. Conclusion: This study provides evidence that polypharmacy is associated with increased risk of mortality in elderly people. The extent to which polypharmacy is the proximate cause rather than a marker of this increase risk remains to be determined.

(c) 2014 S. Karger AG, Basel

\section{Introduction}

In developed countries, the number of older people is increasing, as is their proportion in the population; both declining fertility and increasing life expectancy are contributing to this trend [1]. This increase implies the need

\section{KARGER 125}

E-Mail karger@karger.com www.karger.com/ger 
to adopt policies and manage services with the purpose of combating the social problems affecting a group of people who on their own would be unable to cope with the demands of their living circumstances [2].

Elderly people have their own health characteristics, with a high prevalence of certain disorders such as cardiovascular disease, diabetes mellitus, arterial hypertension, bone and joint problems, and neurodegenerative conditions. Each of these conditions increases fragility and leads to disability [3]. The presence of multiple disease processes further defines elderly people as a population group with a high consumption of healthcare resources, including drugs [3].

Polypharmacy is variously defined as a high number of drugs (e.g. more than 5-10), use of more drugs than clinically indicated, or use of inappropriate medications [4]. Elderly patients are particularly susceptible to issues that arise as a result of polypharmacy - aging affects how their bodies handle medications and they take more medications than younger patients. In recent years, there has been a considerable increase in geriatric polypharmacy [5-9]. For instance, a population-based study of noninstitutionalized people in the United States found that drug consumption, defined as at least one drug, increased with age, reaching close to $90 \%$ in adults aged $\geq 65$ years [9]. Data from the Swedish Prescribed Drug Register also showed a prevalence of polypharmacy in $>5 \%$ of patients in their $40 \mathrm{~s}$, and a prevalence of approximately $12 \%$ among those in their 50s [10].

The impact of polypharmacy on the elderly population is significant. It is associated with poor adherence, drugdrug interactions, medication errors, and adverse drug reactions (including falls, hip fractures, confusion, and delirium), accounting for a significant percentage of potentially preventable emergency room visits and hospitalization $[4,11,12]$. Although polypharmacy is a major and growing public health issue $[13,14]$, only a handful of population-based studies have specifically been performed to assess the association of polypharmacy with risk of mortality [15-17]. This motivated us to assess whether polypharmacy is associated with risk of mortality in a prospective population-based study involving more than 5,000 elderly people in central Spain.

\section{Material and Methods}

\section{Study Population}

Data for these analyses were derived from the Neurological Disorders in Central Spain (NEDICES) study, a longitudinal population-based survey of the prevalence, incidence, and determi- nants of major age-associated conditions of the elderly, including Parkinson's disease (PD), essential tremor, stroke, and dementia [18-31].

Detailed accounts of the study population and sampling methods have been published [18-27]. The survey area consisted of three communities: (1) Margaritas (approx. 14,800 inhabitants), which is a working-class neighborhood in Getafe (Greater Madrid), (2) Lista (approx. 150,000 inhabitants), a professionalclass neighborhood in Salamanca district (central Madrid), and (3) Arévalo (approx. 9,000 inhabitants), the agricultural zone of Arévalo County (125 km northwest of Madrid). Up-to-date lists of residents were generated from population registers. In each community, survey eligibility was restricted to residents aged 65 years or older who were present on December 31, 1993, or during 6 or more months of 1993. Eligible persons who had moved away from the survey area were not traced. In Margaritas and Arévalo, every eligible subject was screened. However, because of the large number of elderly residents in Lista, proportionate stratified random sampling was used to select subjects for screening. All procedures were approved by the ethical standards committees on human experimentation at the university hospitals '12 de Octubre' (Madrid) and 'La Princesa' (Madrid). Written (signed) informed consent was obtained from all enrollees.

\section{Exclusions and Final Sample for Analyses}

Beginning in January 1994, letters explaining the survey and inviting participation were mailed to 6,395 subjects. Of these, 5,914 subjects were deemed eligible for screening and 5,278 subjects $(89.2 \%)$ were screened. The remaining 636 subjects either declined $(292,45.9 \%)$, could not be located due to an address change (292, $45.9 \%)$, or had died $(52,8.2 \%)$. Of the 5,278 participants screened at the baseline evaluation, 217 were excluded because they had no data on daily number of drugs. We further excluded 9 participants due to missing data on death status. Therefore, the final cohort consisted of 5,052 subjects (fig. 1).

The final sample of 5,052 was similar to the base sample of 5,278 participants in terms of gender $[2,918(57.8 \%)$ vs. $3,040(57.6 \%)$ women, $\chi^{2}=0.03, p=0.87$ ], education [669 (13.3\%) vs. $711(13.6 \%)$ illiterate, $\left.\chi^{2}=0.96, p=0.812\right]$, and age $[74.1 \pm 6.9($ median $=73)$ vs. $74.3 \pm 7.0$ (median $=73$ ) years, Mann-Whitney $U$ test, $p=$ $0.306]$.

\section{Study Evaluation}

Briefly, at the time of their baseline assessment (1994-1995), 5,278 elderly subjects were interviewed using a 500-item screening questionnaire that assessed demographic factors and medical conditions. The face-to-face interview included data collection on demographics, current medications (including drugs that affect the central nervous system), and medical conditions. Subjects were asked to bring all medications taken in the past week to the clinic, where the interviewer recorded the name and the dose of each one. Baseline medication use in the current analyses was therefore based on medications taken in the past week.

A short form of the questionnaire was mailed to subjects who refused or were unavailable for face-to-face or telephone screening. This form assessed demographic characteristics, several neurological disorders (PD, essential tremor, stroke, and dementia), current medications, and the name of their family doctor. 
Fig. 1. Flow chart of the study.

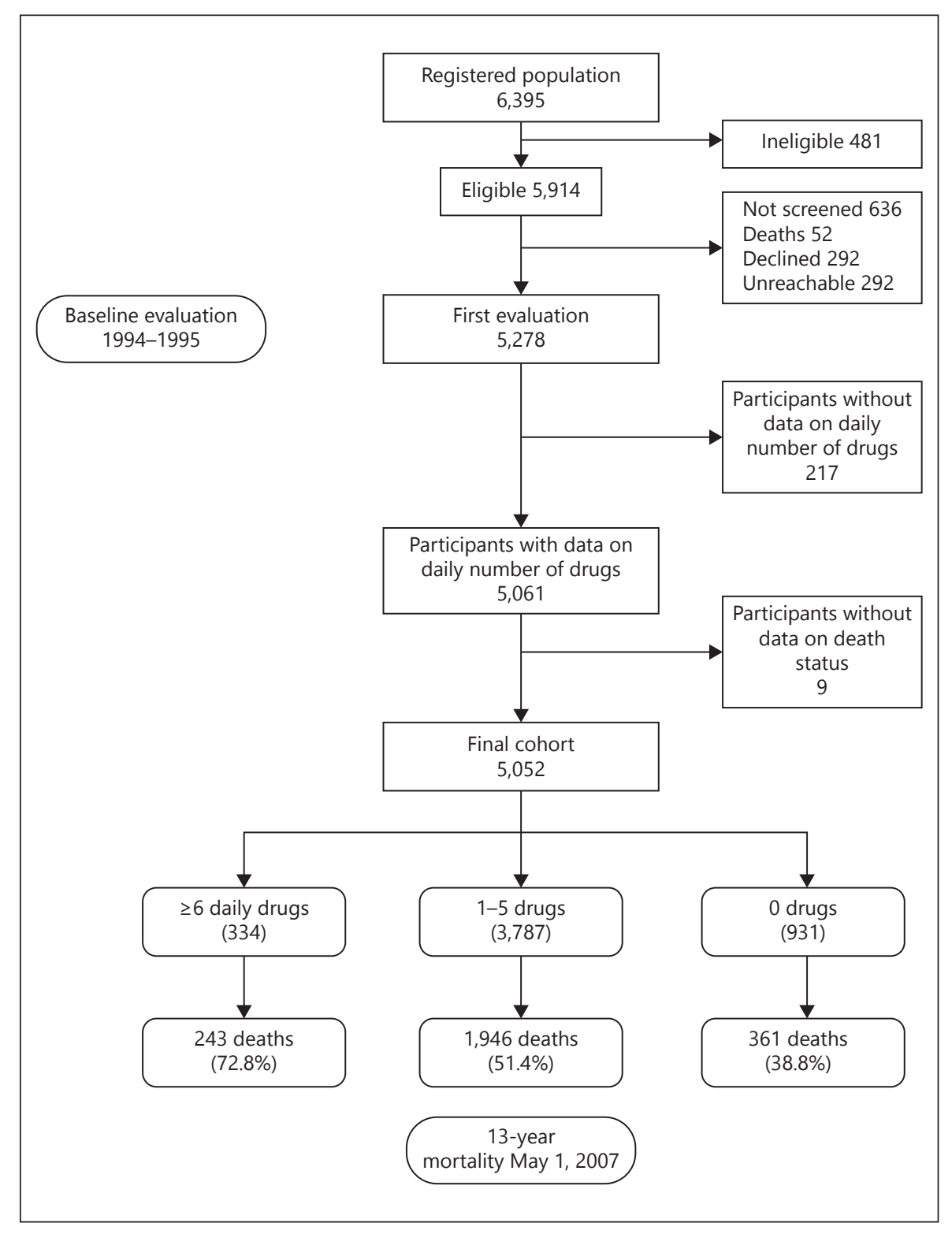

Participants who screened positive for any neurological disease (i.e. PD, essential tremor, stroke, and dementia) were examined by 1 of 8 senior neurologists who met at the inception of the study to establish standardized methods to perform and interpret the examination (F.B.-P., J.B.-L.; see http://www.ciberned.es/estudionedices). For participants who could not be examined, medical records were obtained from their general practitioners, from inpatient hospitalizations, and from neurological specialists (if they had visited one).

The diagnoses of dementia, parkinsonism, and stroke were based on clinical data and medical record review [19, 20, 23-26]. The World Health Organization clinical definition of a stroke was applied $[24,26]$. For the diagnosis of dementia, we applied Diagnostic and Statistical Manual of Mental Disorders (DSM)IV criteria [32] and required evidence of cognitive deficit (neu- ropsychological test battery, clinical mental status examination) as well as evidence of impairment in social or occupational function. Parkinsonism was diagnosed when at least two cardinal signs (resting tremor, rigidity, bradykinesia, or impaired gait/ postural reflexes) were present, and PD was diagnosed in these patients when there were no secondary causes or atypical features $[19,20]$.

There is no consensus in defining polypharmacy [4]. However, a systematic review of the literature stated 'use of six or more concomitant medications' as one of the most cited definitions of polypharmacy [33]. Accordingly, we classified the variable into three categories: (1) 0 drugs, (2) 1-5 drugs, and (3) polypharmacy ( $\geq 6$ drugs).

Follow-up data on death were collected until May 1, 2007. The date of death was obtained from the National Population Register 
of Spain (Instituto Nacional de Estadística). In Spain, all deceased individuals receive a death certificate, completed by a doctor, at the time of death. The certificate is then sent to the local authorities in the municipality where the person had been living, and the information is added to the National Register. The cause of death [using the International Classification of Diseases (ICD) 9th Revision for deaths occurring prior to 1999 (http://www.cdc. gov/nchs/icd/icd9.htm), and the ICD 10th Revision (http://www. cdc.gov/nchs/icd/icd10.htm) for deaths occurring thereafter] was classified by NEDICES investigators into 1 of 6 primary categories: dementia, cerebrovascular disorders, cardiovascular disorders (pulmonary embolism, congestive heart failure, myocardial infarction, heart or aortic rupture, and asystole), respiratory diseases, cancer, and other causes (infections, trauma, and genitourinary or gastrointestinal disorders). In accordance with the recommendations of the World Health Organization, the classification of causes of death were tabulated by the doctors who completed the death certificates, depending on the basic cause of death (http://www.who.int/topics/mortality/en/). This was defined as the illness or injury that started the chain of pathological events which directly led to death (http://www.who.int/topics/ mortality/en/).

\section{Statistical Analyses}

Data analyses were performed in SPSS Version 21.0 (SPSS Inc., Chicago, Ill., USA). Age and comorbidity index (see below) were not normally distributed (Kolmogorov-Smirnov, $\mathrm{p}<0.001$ ), even after log transformation. Therefore, it was compared using nonparametric tests (Mann-Whitney and Kruskal-Wallis tests). The $\chi^{2}$ test was used to analyze categorical variables.

We used Cox proportional hazards models to estimate the relative risk of mortality, which generated hazard ratios (HR) with 95\% confidence intervals (CI). The time variable was the years from the date of the baseline evaluation (1994-1995) to either (1) May 1, 2007 in living participants or (2) the date of death in participants who had died prior to May 1, 2007.

Several potential confounding variables (baseline age, gender, educational level, and comorbidity), which were assessed at the baseline study, were included. The comorbidity index was calculated based on the presence of the following conditions (according to a recently published comorbidity score developed in ambulatory care settings) [34]: atrial fibrillation, cancer, chronic obstructive pulmonary disease, depression, dementia, diabetes, epilepsy (treated), heart failure, myocardial infarction, other psychiatric disorders (psychosis, schizophrenia, or bipolar affective disorder), renal disease, and stroke. The presence of some items resulted in the assignment of more points than others. The score ranged from 0-28 (i.e. all conditions present).

In the Cox proportional hazards analyses, we estimated the risks of mortality in participants with polypharmacy ( $\geq 6$ drugs) and in participants taking between 1 and 5 drugs, each compared with the reference group (nonmedicated participants). In adjusted models, we first considered variables that were associated with both daily number of drugs and death [model 1 (more restrictive criteria for confounding)] and then considered baseline variables that were associated with either daily number of drugs or death [model 2 (less restrictive criteria for confounding)]. In additional analyses, we created tertiles of the number of drugs based on our own data $(\leq 1,2$, and $\geq 3)$ and also treated the number of medications as a continuous variable.
Survival curves for participants with polypharmacy, those taking 1-5 medications, and those who were nonmedicated were calculated using the Kaplan-Meier method. The log-rank test was used to compare the differences between curves.

\section{Results}

Of 5,052 participants, 2,550 (50.5\%) died over a median follow-up of 6.5 years (range: 0.01-13.3), including $361(28.8 \%)$ deaths among 931 nonmedicated participants, $1,946(51.4 \%)$ deaths among 3,787 participants who were taking between 1 and 5 drugs daily, and 243 (72.8\%) deaths among 334 participants on polypharmacy (fig. 1). There were significant differences in age, gender, and medical comorbidities when participants in the three drug-use categories were compared (table 1). As expected, deceased participants were significantly older, predominantly men, and had more medical comorbidity than living participants (table 2).

The cause of death noted on the death certificates differed significantly by number of drugs consumed (table 3). Cancer and dementia were reported significantly less often in participants on polypharmacy than in those who were taking between 1 and 5 drugs or in those who were nonmedicated. In contrast, cerebrovascular diseases and respiratory diseases were reported significantly more often in participants on polypharmacy than in those taking between 1 and 5 drugs or in those who were nonmedicated (table 3).

In an unadjusted Cox model, risk of mortality was increased in participants on polypharmacy $(\mathrm{HR}=2.78,95 \%$ CI: 2.36-3.27, $\mathrm{p}<0.001)$ and in those taking between 1 and 5 drugs ( $\mathrm{HR}=1.47,95 \% \mathrm{CI}: 1.31-1.64, \mathrm{p}<0.001)$ versus those who were nonmedicated (reference group). In a Cox model that adjusted for baseline age, gender, comorbidity index (13 conditions), PD, current smoker, and current drinker (i.e. variables that were associated with both daily number of drugs and death), the risk of mortality remained increased in participants on polypharmacy $(\mathrm{HR}=1.83,95 \%$ CI: 1.51-2.21, $\mathrm{p}<0.001$; model 1 in table 4).

The results did not change in a Cox model that adjusted for variables that were associated with either number of drugs or death [baseline age, gender, educational level, geographical area, comorbidity index (13 conditions), $\mathrm{PD}$, current smoker, and current drinker; model 2 in table 4]. We also considered a number of different forms of the age variable; thus, when we added quadratic and cubic forms of age to model 2, along with age itself, the 
Table 1. Baseline (1994-1995) characteristics of the study participants $(n=5,052)$, according to number of drugs consumed

\begin{tabular}{|c|c|c|c|c|}
\hline & \multicolumn{3}{|c|}{ Number of drugs consumed } & \multirow[t]{2}{*}{$\mathrm{p}$} \\
\hline & $\begin{array}{l}0 \\
(\mathrm{n}=931)\end{array}$ & $\begin{array}{l}1-5 \\
(\mathrm{n}=3,787)\end{array}$ & $\begin{array}{l}\geq 6 \\
(\mathrm{n}=334)\end{array}$ & \\
\hline Age, years & $72.7 \pm 6.7(71)$ & $74.4 \pm 6.9(73)$ & $75.4 \pm 6.7(74)$ & $<0.001^{\mathrm{c}}$ \\
\hline Gender, women & $421(45.2 \%)$ & $2,320(61.3 \%)$ & $177(53.0 \%)$ & $<0.001^{\mathrm{d}}$ \\
\hline \multicolumn{5}{|l|}{ Educational level $^{\mathrm{a}}$} \\
\hline Illiterate & $107(11.6 \%)$ & $510(13.6 \%)$ & $52(15.6 \%)$ & \multirow{4}{*}{$0.187^{\mathrm{C}}$} \\
\hline Can read and write & $372(40.2 \%)$ & $1,538(40.9 \%)$ & $136(40.7 \%)$ & \\
\hline Primary studies & $327(35.3 \%)$ & $1,194(31.7 \%)$ & $96(28.7 \%)$ & \\
\hline Secondary and higher studies & $120(13.0 \%)$ & $521(13.8 \%)$ & $50(15.0 \%)$ & \\
\hline \multicolumn{5}{|l|}{ Geographical area } \\
\hline Lista & $207(22.2 \%)$ & $1,185(31.3 \%)$ & $130(38.9 \%)$ & \multirow{3}{*}{$<0.001^{\mathrm{C}}$} \\
\hline Arévalo & $356(38.2 \%)$ & $1,340(35.4 \%)$ & $84(25.1 \%)$ & \\
\hline Margaritas & $368(39.5 \%)$ & $1,262(33.3 \%)$ & $120(35.9 \%)$ & \\
\hline Comorbidity index ${ }^{\mathrm{b}}$ & $0.6 \pm 1.2(0)$ & $1.2 \pm 1.5(1)$ & $2.4 \pm 1.9(2)$ & $<0.001^{\mathrm{c}}$ \\
\hline $\mathrm{PD}$ & $4(0.4 \%)$ & $69(1.8 \%)$ & $7(2.1 \%)$ & $0.007^{\mathrm{d}}$ \\
\hline Current smoker ${ }^{\mathrm{a}}$ & $139(19.6 \%)$ & $324(10.4 \%)$ & $21(7.1 \%)$ & $<0.001^{\mathrm{d}}$ \\
\hline Current drinker ${ }^{\mathrm{a}}$ & $329(46.3 \%)$ & $971(31.3 \%)$ & $66(22.4 \%)$ & $<0.001^{\mathrm{d}}$ \\
\hline
\end{tabular}

Means \pm SD (median) and $\mathrm{n}(\%)$ are reported. ${ }^{\mathrm{a}}$ Data on some participants were missing. ${ }^{\mathrm{b}}$ Comorbidity included the following conditions: atrial fibrillation, cancer, chronic obstructive pulmonary disease, depression, dementia, diabetes, epilepsy (treated), heart failure, myocardial infarction, other psychiatric disorders (psychosis, schizophrenia, or bipolar affective disorder), renal disease, and stroke. ${ }^{c} \mathrm{~A}$ Kruskal-Wallis test was used for age and comorbidity index. ${ }^{\mathrm{d}} \mathrm{A} \chi^{2}$ test for categorical variables.

Table 2. Demographic and clinical characteristics of cohort stratified by mortality

\begin{tabular}{lccc}
\hline & $\begin{array}{l}\text { Alive } \\
(\mathrm{n}=2,502)\end{array}$ & $\begin{array}{c}\text { Died } \\
(\mathrm{n}=2,550)\end{array}$ & $\mathrm{p}$ \\
\hline Age in years & $71.2 \pm 5.1(70)$ & $77.0 \pm 7.2(76)$ & $<0.001^{\mathrm{c}}$ \\
Gender, women & $1,636(65.4 \%)$ & $1,282(50.3 \%)$ & $<0.001^{\mathrm{d}}$ \\
Educational level & & \\
Illiterate & $299(12.0 \%)$ & $370(14.6 \%)$ & $0.028^{\mathrm{d}}$ \\
Can read and write & $1,015(40.7 \%)$ & $1,031(40.7 \%)$ & \\
Primary studies & $835(33.5 \%)$ & $782(30.9 \%)$ & \\
Secondary and higher studies & $343(13.8 \%)$ & $348(13.7 \%)$ & \\
Geographical area & & & \\
$\quad$ Lista & $715(28.6 \%)$ & $807(31.6 \%)$ & $0.010^{\mathrm{d}}$ \\
$\quad$ Arévalo & $873(34.9 \%)$ & $1.5 \pm 1.7(1)$ & $<0.001^{\mathrm{c}}$ \\
$\quad$ Margaritas & $914(36.5 \%)$ & $65(2.5 \%)$ & $<0.001^{\mathrm{d}}$ \\
PD & $0.8 \pm 1.2(0)$ & $263(12.9 \%)$ & $0.027^{\mathrm{d}}$ \\
Current smoker & $15(0.6 \%)$ & $646(31.7 \%)$ & $0.040^{\mathrm{d}}$ \\
Current drinker & $221(10.7 \%)$ & &
\end{tabular}

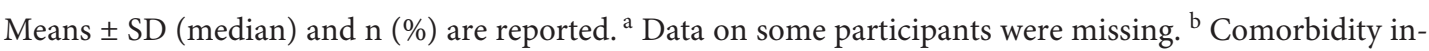
cluded the following conditions: atrial fibrillation, cancer, chronic obstructive pulmonary disease, depression, dementia, diabetes, epilepsy (treated), heart failure, myocardial infarction, other psychiatric disorders (psychosis, schizophrenia, or bipolar affective disorder), renal disease, and stroke. ${ }^{c}$ Mann-Whitney $U$ test. ${ }^{d} \chi^{2}$ test. 
Table 3. Basic cause of death by number of drugs consumed

\begin{tabular}{lcrrr}
\hline & Nonmedicated & \multicolumn{1}{l}{$1-5$} & $\geq 6$ & $\mathrm{p}^{\mathrm{a}}$ \\
\hline Dementia & $38(10.5 \%)$ & $127(6.5 \%)$ & $5(2.1 \%)$ & $<0.001$ \\
Cerebrovascular disorders & $23(6.4 \%)$ & $174(8.9 \%)$ & $16(6.6 \%)$ & 0.155 \\
Cardiovascular diseases & $75(20.8 \%)$ & $556(28.6 \%)$ & $85(35.0 \%)$ & $<0.001$ \\
Respiratory diseases & $39(10.8 \%)$ & $272(14.0 \%)$ & $58(23.9 \%)$ & $<0.001$ \\
Cancer & $130(36.0 \%)$ & $457(23.5 \%)$ & $37(15.2 \%)$ & $<0.001$ \\
Other causes & $56(15.5 \%)$ & $360(18.5 \%)$ & $42(17.3 \%)$ & 0.381 \\
\hline Total & $361(100 \%)$ & $1,946(100 \%)$ & $243(100 \%)$ & - \\
\hline
\end{tabular}

Values represent $\mathrm{n}(\%) .{ }^{\mathrm{a}} \chi^{2}$ test.

Table 4. Predictors of mortality in the NEDICES cohort

\begin{tabular}{|c|c|c|c|c|c|c|}
\hline & \multicolumn{3}{|l|}{ Model 1} & \multicolumn{3}{|c|}{ Model 2} \\
\hline & HR & $95 \% \mathrm{CI}$ & $\mathrm{p}$ & HR & $95 \% \mathrm{CI}$ & $\mathrm{p}$ \\
\hline \multicolumn{7}{|l|}{ Daily number of drugs } \\
\hline$\geq 6$ & 1.83 & $1.51-2.21$ & $<0.001$ & 1.82 & $1.50-2.20$ & $<0.001$ \\
\hline $1-5$ & 1.32 & $1.15-1.51$ & $<0.001$ & 1.31 & $1.15-1.50$ & $<0.001$ \\
\hline Nonmedicated (reference) & 1.00 & - & - & 1.00 & - & - \\
\hline Age (years) & 1.10 & $1.09-1.11$ & $<0.001$ & 1.10 & $1.09-1.11$ & $<0.001$ \\
\hline Gender (women) & 0.55 & $0.50-0.61$ & $<0.001$ & 0.55 & $0.50-0.61$ & $<0.001$ \\
\hline \multicolumn{7}{|l|}{ Educational level } \\
\hline Illiterate & not included & - & - & 1.03 & $0.86-1.23$ & 0.757 \\
\hline Can read and write & not included & - & - & 0.99 & $0.86-1.14$ & 0.894 \\
\hline Primary studies & not included & - & - & 0.97 & $0.83-1.12$ & 0.654 \\
\hline$\geq$ Secondary studies, reference & not included & - & - & 1.00 & - & - \\
\hline \multicolumn{7}{|l|}{ Geographical area } \\
\hline Lista & 1.26 & $1.13-1.40$ & $<0.001$ & 1.27 & $1.13-1.43$ & $<0.001$ \\
\hline Arévalo & 0.97 & $0.87-1.08$ & 0.546 & 0.98 & $0.88-1.10$ & 0.760 \\
\hline Margaritas (reference) & 1.00 & - & - & 1.00 & - & - \\
\hline Comorbidity index $^{\mathrm{a}}$ & 1.18 & $1.15-1.21$ & $<0.001$ & 1.18 & $1.15-1.21$ & $<0.001$ \\
\hline $\mathrm{PD}$ & 1.66 & $1.27-2.17$ & $<0.001$ & 1.65 & $1.26-2.16$ & $<0.001$ \\
\hline Current smoker & 1.34 & $1.17-1.54$ & $<0.001$ & 1.34 & $1.17-1.54$ & $<0.001$ \\
\hline Current drinker & 0.81 & $0.73-0.90$ & $<0.001$ & 0.81 & $0.73-0.90$ & $<0.001$ \\
\hline
\end{tabular}

HR was 1.82 (95\% CI: $1.50-2.20, \mathrm{p}<0.001)$ for participants on polypharmacy. In that model, neither the quadratic nor the cubic forms of age were independently associated with outcome (both $\mathrm{p}=1.00$ ).

In additional analyses, we created tertiles of numbers of medications based on our own data $(\leq 1,2$, and $\geq 3$ ). The results were similar: unadjusted HR for participants within the highest tertile of number of drugs consumed versus those in the lowest tertile $=1.45(95 \%$ CI: $1.30-1.62, \mathrm{p}<0.001)$, and model 2 -adjusted HR = 1.45 (95\% CI: $1.30-1.61, \mathrm{p}<0.001$ ). We also treated number of drugs as a continuous variable and polypharmacy was associated with higher mortality: unadjusted HR $=1.16(95 \%$ CI: $1.14-1.18, \mathrm{p}<0.001)$ and model 2-adjusted HR $=1.10$ (95\% CI: $1.08-1.13, \mathrm{p}<$ $0.001)$. 


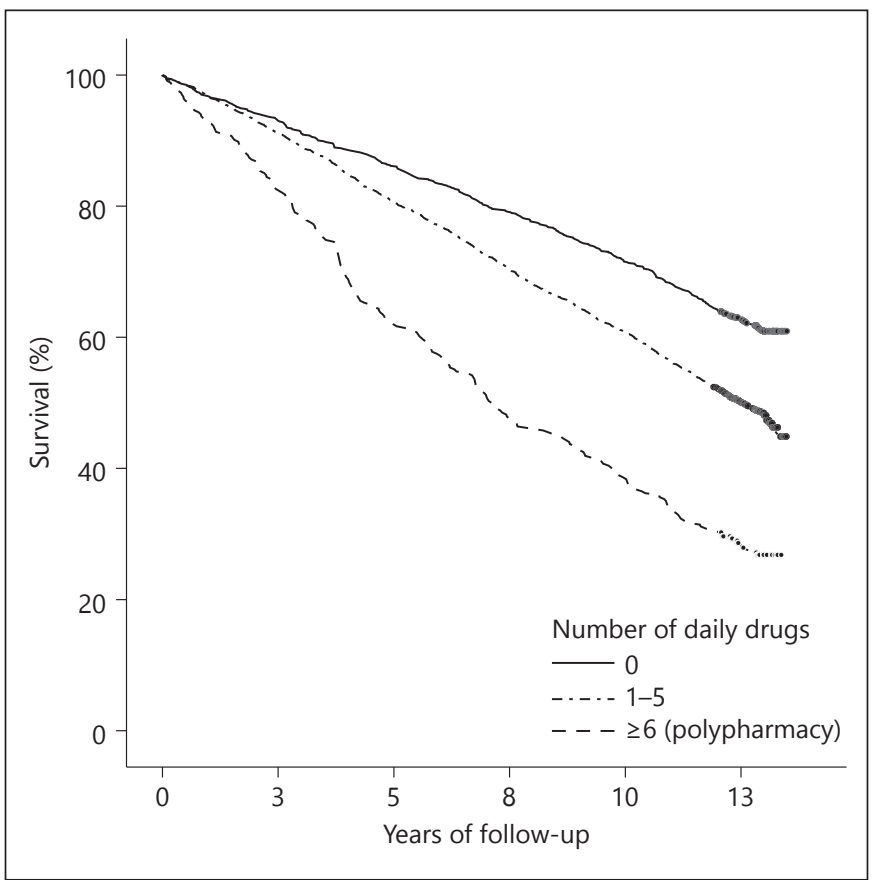

Fig. 2. Kaplan-Meier curves of percent survival for participants with polypharmacy vs. those taking between 1 and 5 daily medications vs. nonmedicated participants $(\log -\operatorname{rank} \mathrm{p}<0.001)$.

The Kaplan-Meier curves for overall survival (fig. 2) showed the cohort of participants with polypharmacy to be at an increased risk of death (log-rank $\mathrm{p}<0.001)$.

\section{Discussion}

Using follow-up mortality data collected as part of a prospective population-based study, we demonstrated that polypharmacy was an independent predictor of mortality. We acknowledge that elderly patients are more likely to have multiple diseases and more comorbidity, and are therefore likely to use more medications [35]. However, even after adjusting for a variety of potentially confounding comorbid medical conditions, polypharmacy continued to be associated with increased risk of mortality. Assessing the daily number of drugs consumed might provide useful mortality risk stratification in the community-dwelling elderly. It remains to be determined whether detecting and lowering the extent of polypharmacy could improve the health risks of communitydwelling elderly individuals.

Our results are in agreement with prior surveys that have analyzed the risk of mortality according to the num- ber of drugs consumed, using a population-based approach $[15,16]$. In a population of 3,050 communitybased Mexican-American older adults, living in the southwestern United States, use of more than four different medications was associated with mortality, independent of age, socioeconomic status, or chronic disease status and/or severity [15]. In another population-based study involving elderly persons aged $\geq 75$ years $(\mathrm{n}=700)$ living in the city of Kuopio, Finland, two separate analyses were carried out [16]. In the first phase, participants (aged $\geq 75$ years, $\mathrm{n}=601$ ) were followed from 1998 (baseline) to 2002 . In the second phase, survivors (aged $\geq 80$ years, $\mathrm{n}=339$ ) were followed from 2003 to 2007 [16]. In the first phase, the univariate model showed an association between excessive polypharmacy ( $\geq 10$ drugs) and mortality $(\mathrm{HR}=$ 2.53, 95\% CI: 1.83-3.48) [16]; however, after adjustment for demographics and other variables measuring functional and cognitive status, the association between excessive polypharmacy and mortality did not remain statistically significant [16]. In the second phase, the association between excessive polypharmacy and mortality ( $\mathrm{HR}=$ 2.23, 95\% CI: 1.21-4.12) remained significant after adjustments [16]. In contrast, in the ICARe Dicomano study, involving 1,022 elderly people from a small town in Tuscany, Italy, in univariate analysis, mortality was twice as high in participants with polypharmacy ( $\geq 6$ drugs) [17]; however, in multivariable models, polypharmacy, was no longer associated with an increased risk of death [17].

The extent to which polypharmacy is the proximate cause rather than a marker of increased risk of mortality remains to be determined. Polypharmacy could contribute to increased risk of mortality in the elderly in several ways. First, elderly patients are at risk for severe adverse drug events since the physiologic changes that occur with ageing make the body more sensitive to the effects of drugs [36]. The cumulative effects of multiple medications on the renal or hepatic systems would initiate a cascade of interactions in these older adults, who already suffer from multiple comorbidities [15]. Second, drugs that affect the central nervous system may cause drowsiness, impaired memory, confusion, and prolonged sedation, which increase an elderly patient's risk for falls, fractures, and aspiration pneumonias [37]. Third, drug-disease interactions, in which a medication worsens a disease condition, are also common among elderly patients. Finally, polypharmacy is potentially harmful because it increases the probability of adverse drug-drug interactions [38, 39].

Our study has limitations. First, community-dwelling elders might also take self-prescribed over-the-counter drugs or complementary and alternative medicines, 
which they might not tell their doctor about. Although this would imply an underestimation of drug use, it would be compensated in part by the lack of adherence to therapy, very often found among the elderly population [40]. Second, data on drug exposure were available at baseline, but not for any intermediate time intervals between baseline and follow-up. Such data would have been of value in terms of assessing variation in drug exposure over time.

This study also had several strengths. First, the study was population-based, allowing us to assess a group of participants who were unselected for treatment considerations. Second, the assessments were conducted prospectively in a standardized manner. Finally, we were able to adjust for the potential confounding effects of a number of important factors.

Using a prospective, population-based design, we demonstrated that polypharmacy in community-dwelling elders was associated with increased risk of mortality. By asking patients about the usage of drugs, practitioners might be better positioned to identify patients with poorer prognoses.

\section{Acknowledgments}

Additional information about collaborators and detailed funding of the NEDICES Study can be found on the Web (http://www. ciberned.es/estudio-nedices). The Spanish Health Research Agency and the Spanish Office of Science and Technology supported NEDICES. Dr. Vega-Quiroga is supported by NINDS No. R01 NS039422 from the National Institutes of Health, Bethesda, Md., USA. Dr. Bermejo-Pareja is supported by NINDS No. R01 NS039422 from the National Institutes of Health, Bethesda, Md., USA, the Commission of the European Union (grant ICT-2011287739, NeuroTREMOR), and the Spanish Health Research Agency (grant FIS PI11/01508). Dr. Elan D. Louis has received research support from the National Institutes of Health, Bethesda, Md., USA: NINDS No. R01 NS042859 (principal investigator), NINDS No. R01 NS085136 (principal investigator), NINDS No. R01 NS39422 (principal investigator), NINDS No. T32 NS07153-24 (principal investigator), NINDS No. R01 NS073872 (principal investigator), NINDS No. R21 NS077094 (coinvestigator), and NINDS No. R01 NS36630 (coinvestigator), as well as the Parkinson's Disease Foundation (principal investigator). Dr. BenitoLeón is supported by NINDS No. R01 NS039422 from the National Institutes of Health, Bethesda, Md., USA, the Commission of the European Union (grant ICT-2011-287739, NeuroTREMOR), and the Spanish Health Research Agency (grant FIS PI12/01602).

\section{References}

1 Lutz W, Sanderson W, Scherbov S: The coming acceleration of global population ageing. Nature 2008;451:716-719.

2 Remington PL, Brownson RC, Wegner MV: American Public Health Association: Chronic Disease Epidemiology and Control, ed 3. Washington, American Public Health Association, 2010.

-3 Guralnik JM, Kaplan GA: Predictors of healthy aging: prospective evidence from the alameda county study. Am J Public Health 1989;79:703-708

4 Farrell B, Shamji S, Monahan A, French Merkley V: Reducing polypharmacy in the elderly: cases to help you 'rock the boat'. Can Pharm J (Ott) 2013;146:243-244.

5 Carbonin P, Pahor M, Bernabei R, Sgadari A: Is age an independent risk factor of adverse drug reactions in hospitalized medical patients? J Am Geriatr Soc 1991;39:1093-1099.

-6 Haider SI, Johnell K, Thorslund M, Fastbom $\mathrm{J}$ : Analysis of the association between polypharmacy and socioeconomic position among elderly aged $>$ or $=77$ years in Sweden. Clin Ther 2008;30:419-427.

7 Colloca G, Tosato M, Vetrano DL, Topinkova E, Fialova D, Gindin J, van der Roest HG, Landi F, Liperoti R, Bernabei R, Onder G: Inappropriate drugs in elderly patients with severe cognitive impairment: results from the SHELTER study. PLoS One 2012;7:e46669.

-8 Vetrano DL, Tosato M, Colloca G, Topinkova E, Fialova D, Gindin J, van der Roest HG, Lan- di F, Liperoti R, Bernabei R, Onder G: Polypharmacy in nursing home residents with severe cognitive impairment: results from the SHELTER study. Alzheimers Dement 2013;9: 587-593.

-9 Kaufman DW, Kelly JP, Rosenberg L, Anderson TE, Mitchell AA: Recent patterns of medication use in the ambulatory adult population of the United States: the Slone survey. JAMA 2002;287:337-344.

10 Hovstadius B, Hovstadius K, Astrand B, Petersson G: Increasing polypharmacy - an individual-based study of the Swedish population 2005-2008. BMC Clin Pharmacol 2010;10:16.

$\checkmark 11$ Shah BM, Hajjar ER: Polypharmacy, adverse drug reactions, and geriatric syndromes. Clin Geriatr Med 2012;28:173-186.

12 Zed PJ, Abu-Laban RB, Balen RM, Loewen PS, Hohl CM, Brubacher JR, Wilbur K, Wiens MO, Samoy LJ, Lacaria K, Purssell RA: Incidence, severity and preventability of medication-related visits to the emergency department: a prospective study. CMAJ 2008; 178 : 1563-1569.

13 Colley CA, Lucas LM: Polypharmacy: the cure becomes the disease. J Gen Intern Med 1993; 8:278-283.

14 Payne RA, Avery AJ: Polypharmacy: one of the greatest prescribing challenges in general practice. Br J Gen Pract 2011;61:83-84.

15 Espino DV, Bazaldua OV, Palmer RF, Mouton CP, Parchman ML, Miles TP, Markides K: Suboptimal medication use and mortality in an older adult community-based cohort: results from the Hispanic EPESE Study. J Gerontol A Biol Sci Med Sci 2006;61:170175.

16 Jyrkkä J, Enlund H, Korhonen MJ, Sulkava R, Hartikainen S: Polypharmacy status as an indicator of mortality in an elderly population. Drugs Aging 2009;26:10391048.

17 Pozzi C, Lapi F, Mazzaglia G, Inzitari M, Boncinelli M, Geppetti P, Mugelli A, Marchionni $\mathrm{N}$, Di Bari M: Is suboptimal prescribing a risk factor for poor health outcomes in community-dwelling elders? The ICARe Dicomano study. Pharmacoepidemiol Drug Saf 2010;19: 954-960.

18 Benito-León J, Bermejo-Pareja F, Morales JM, Vega S, Molina JA: Prevalence of essential tremor in three elderly populations of central Spain. Mov Disord 2003;18:389-394.

19 Benito-León J, Bermejo-Pareja F, Rodríguez J, Molina JA, Gabriel R, Morales JM; Neurological Disorders in Central Spain (NEDICES) Study Group: Prevalence of PD and other types of parkinsonism in three elderly populations of central Spain. Mov Disord 2003;18:267-274.

20 Benito-León J, Bermejo-Pareja F, MoralesGonzález JM, Porta-Etessam J, Trincado R, Vega S, Louis ED; Neurological Disorders in Central Spain (NEDICES) Study Group: Incidence of Parkinson disease and parkinsonism in three elderly populations of central Spain. Neurology 2004;62:734-741. 
21 Morales JM, Bermejo FP, Benito-León J, Rivera-Navarro J, Trincado R, Gabriel SR, Vega S; NEDICES Study Group: Methods and demographic findings of the baseline survey of the NEDICES cohort: a door-to-door survey of neurological disorders in three communities from central Spain. Public Health 2004; 118:426-433.

22 Benito-León J, Bermejo-Pareja F, Louis ED; Neurological Disorders in Central Spain (NEDICES) Study Group: Incidence of essential tremor in three elderly populations of central Spain. Neurology 2005;64:1721-1725.

-23 Louis ED, Benito-León J, Bermejo-Pareja F; Neurological Disorders in Central Spain (NEDICES) Study Group: Self-reported depression and anti-depressant medication use in essential tremor: cross-sectional and prospective analyses in a population-based study. Eur J Neurol 2007;14:1138-1146.

24 Bermejo-Pareja F, Benito-León J, Vega S, Medrano MJ, Román GC; Neurological Disorders in Central Spain (NEDICES) Study Group: Incidence and subtypes of dementia in three elderly populations of central Spain. J Neurol Sci 2008;264:63-72.

25 Louis ED, Benito-León J, Bermejo-Pareja F; Neurological Disorders in Central Spain (NEDICES) Study Group: Philadelphia geriatric morale scale in essential tremor: a population-based study in three Spanish communities. Mov Disord 2008;23:1435-1440.

-26 Díaz-Guzmán J, Bermejo-Pareja F, BenitoLeón J, Vega S, Gabriel R, Medrano MJ; Neurological Disorders in Central Spain (NEDICES) Study Group: Prevalence of stroke and transient ischemic attack in three elderly populations of central Spain. Neuroepidemiology 2008;30:247-253.
27 Bermejo-Pareja F, Benito-León J, Vega S, Olazarán J, de Toledo M, Díaz-Guzmán J, Sánchez-Sánchez F, Morales-González JM, Trincado R, Portera-Sanchez A, Roman GC: Consistency of clinical diagnosis of dementia in NEDICES: a population-based longitudinal study in Spain. J Geriatr Psychiatry Neurol 2009;22:246-255.

28 Benito-León J, Louis ED, Bermejo-Pareja F; Neurological Disorders in Central Spain (NEDICES) Study Group: Population-based case-control study of morale in Parkinson's disease. Eur J Neurol 2009;16:330-336.

29 Martínez-Salio A, Benito-León J, DíazGuzmán J, Bermejo-Pareja F: Cerebrovascular disease incidence in central Spain (NEDICES): a population-based prospective study. J Neurol Sci 2010;298:85-90.

30 Vega S, Benito-León J, Bermejo-Pareja F, Medrano MJ, Vega-Valderrama LM, Rodríguez C, Louis ED: Several factors influenced attrition in a population-based elderly cohort: neurological disorders in central Spain study. J Clin Epidemiol 2010;63:215-222.

31 Benito-León J, Louis ED, Rivera-Navarro J, Medrano MJ, Vega S, Bermejo-Pareja F: Low morale is associated with increased risk of mortality in the elderly: a population-based prospective study (NEDICES). Age Ageing 2010;39:366-373.
32 Diagnostic and Statistical Manual of Mental Disorders DSM-IV. Washington, American Psychiatric Association, 1994.

33 Bushardt RL, Massey EB, Simpson TW, Ariail JC, Simpson KN: Polypharmacy: misleading, but manageable. Clin Interv Aging 2008;3: 383-389.

34 Carey IM, Shah SM, Harris T, DeWilde S, Cook DG: A new simple primary care morbidity score predicted mortality and better explains between practice variations than the Charlson index. J Clin Epidemiol 2013;66: 436-444.

35 Zhan C, Sangl J, Bierman AS, Miller MR, Friedman B, Wickizer SW, Meyer GS: Potentially inappropriate medication use in the community-dwelling elderly: findings from the 1996 Medical Expenditure Panel Survey. JAMA 2001;286:2823-2829.

36 Abrams WB, Beers MH: Clinical pharmacology in an aging population. Clin Pharmacol Ther 1998;63:281-284.

- 37 Fick DM, Cooper JW, Wade WE, Waller JL, Maclean JR, Beers MH: Updating the Beers criteria for potentially inappropriate medication use in older adults: results of a US consensus panel of experts. Arch Intern Med 2003;163:2716-2724.

38 Monane M, Monane S, Semla T: Optimal medication use in elders. Key to successful aging. West J Med 1997;167:233-237.

-39 Tanaka E: Clinically significant pharmacokinetic drug interactions between antiepileptic drugs. J Clin Pharm Ther 1999;24:87-92.

40 Lassen LC: Patient compliance in general practice. Scand J Prim Health Care 1989;7: 179-180. 